\title{
LA ACTUALIdAd de las CATEgorías GRAMSCIANAS PARA EL ANÁLISIS DE LA REESTRUCTURACIÓN Productiva en Curso
}

\section{Ruth Sosa}

RESÚMEN: El presente artículo tiene como objetivo trabajar algunas categorías gramscianas y actualizarlas como categorías de análisis del capitalismo contemporáneo. Privilegiaremos, aqui, el aspecto concerniente a la restructuración productiva en curso. Como punto de partida intentamos recuperar el concepto de hegemonía presente en las formulaciones de los Cuadernos de la Cárcel. Todavía en este punto ganan relevancia las categorías crisis orgánica y revolución pasiva. Estas categorías demuestran su eficacia en la comprensión de las crisis del capital y en sus tentativas de resolución así como de la intervención estratégica de las clases subalternas en el proceso de construcción de su hegemonía.

En un segundo momento, y a partir de los elementos previamente trabajados, desarrollamos algunas tesis presentes en los textos relativos a "Americanismo y Fordismo".

A modo de "conclusión" planteamos que el capitalismo contemporáneo, bajo la fachada ideológica de la "revolución científico-tecnológica" asume una clara estrategia de pasivización cuyo trazo esencial es el transformismo, aspecto distintivo, según Gramsci, para designar a la Revolución Pasiva.

PALABRAS CLAVES: Gramsci; Crisis orgánica; hegemonía; revolución pasiva; capitalismo; fordismo; reestruturación productiva. 
El presente artículo se incribe en la preocupación que objetiva trabajar algunas categorias analíticas del marxista italiano Antonio Gramsci en lo concerniente a un aspecto crucial del capitalismo contemporáneo: la reestructuración productiva en curso.

En las actuales circunstancias, pocos intelectuales se han focalizado en el estudio de la actual coyuntura del capitalismo a partir de los elementos analíticos - estratégicos legados por Gramsci.

En los últimos años, se ha iniciado una interesante discusión al respecto, en el ámbito del Instituto de Filosofia y Ciencias Humanas de la UNICAMP. Un grupos de intelectuales - Edmundo Fernandes Dias, 1996 - 1997; Angela Tude de Souza, 1994; Ruy Braga, 1996 - 1997, entre outros/as - se colocaron el desafío de actualizar la teoria gramsciana para el análisis del capitalismo contemporáneo. Los aportes de estos autores inauguraron una línea casi inédita en el campo de investigación en las ciencias sociales. Así fueron ganando relevancia diversos términos que nos servirán como instrumentos analíticos para uma alternativa válida de comprensión de la fase actual del capitalismo.

\section{Notas Sobre EL CONCEPTO DE HEGEMONIA EM GRAMSCI}

Gramsci va a construir su teoría de la hegemonía a partir de cinco conceptos fundamentales: crisis orgánica, revolución pasiva-guerra de posición, bloque histórico y la cuestión en torno a la función de los intelectuales. Estas son categorías intermediarias que sirven para pensar la afirmación de la hegemonía. Categorías que son a la vez analíticas y estratégicas en su forma concreta de historicidad.

Gramsci va a explicitar que es preciso saber distinguir en la estructura los movimientos orgánicos (considerados relativamente permanentes) y los coyunturales (que aparecen como ocasionales, 
inmediatos, casi accidentales) ${ }^{1}$. Estos fenómenos de carácter orgánico son los que posibilitan una crítica bistórico-social. Não obstante, en estos análisis histórico-políticos, frecuentemente se comete el error de no saber encontrar la justa relación entre lo que es orgánico y lo que es ocasional. Por eso, es necesario que el problema de las relaciones entre estructura y superestructura sea situado com mayor exactitud y resuelto para llegar, asi, a un justo análisis de las fuerzas que actuan en la bistória de un determinado periodo y a la definición de la relación entre éstas. (Gramsci, 1976, p.46)

En este punto, Gramsci va a precisar su comprensión acerca de lo que significa una crisis orgânica.

"Se verifica una crisis que, a veces, se prolonga por decena de años. Esta duración excepcional quiere decir que se revelaron (maduraron) contradicciones incurables en la estructura y que las fuerzas politicas que actuan positivamente para conservar $y$ defender la propia estructura se esfuerzan para sanearlas dentro de ciertos limites $y$ superarlas. Estos esfuerzos incesantes y perseverantes (pues ninguna forma social jamás confesará que fue superada) forman el terreno de lo 'ocasional' sobre el cual se organizan las fuerzas antagónicas, que tiendem a demostrar (demostración que, en último análisis, sólo se realiza y es 'verdadera' cuando se torna nueva realidad, cuando las fuerzas antagónicas triunfan; mas inmediatamente se desarrolla una serie de polémicas ideológicas, religiosas, filosóficas, políticas, jurídicas, etc., cuya concreción puede ser evaluada por la medida en que logran convencer y deslocan lo preexistente dispositivo de fuerzas sociales) que ya existen condiciones necesarias y suficientes para que determinados encargos puedan $y$, por consiguiente, deban ser resueltos bistóricamente." (1976, p.46)

'Es necesario aclarar que este tipo de distinciones tales como estructura-coyuntura, así como por ejemplo, Estado-Sociedad Civil; estructura-superestructura, etc., en Gramsci, son estrictamente a nivel metodológico y operacional. El conjunto de estos pares de conceptos constituyen una unidad orgánica. 
Por lo tanto, los períodos de crisis orgánica son caracterizados, fundamentalmente, por el aislamiento de determinados grupos sociales en relación a sus representantes, y en este sentido, se determinan situaciones de cresciente contraste entre representantes y representados. Se verifica una crisis de autoridad que, en realidad, es una crisis de hegemonía de la clase dirigente o una crisis del Estado en general. Así, la crisis puede originarse porque la clase dirigente falló en un determinado emprendimiento político por el cual pidió o impuso por la fuerza el consentimiento de las grandes masas (como la guerra), o porque amplias masas (especialmente de campesinos y de pequeños burgueses intelectuales) pasaron repentinamente de la pasividad política a un otro nivel de actividad presentando reivindicaciones, que en su complejo desorganizado constituyen una revolución (Gramsci, 1976, p.54-55).

La distinción entre 'movimientos' y hechos orgánicos y movimentos y hechos de 'coyuntura' u ocasionales puede ser aplicada de acuerdo con Gramsci- a todos los tipos de situación, tanto aquellas en que se manifiesta un proceso regresivo de crisis aguda como en aquellas situaciones de prosperidad o aquellas en las que se verifica una estagnación de las fuerzas productivas.

Una cuestión que nos parece fundamental para tener en cuenta es que toda situación de crisis orgánica abre nuevas posibilidades de embates entre las classes $y$, consecuentemente, nuevas posibilidades de hegemonía. La situación de crisis orgánica actualiza los movimientos de la estructura a través de una nueva coyuntura, es decir, actualiza las fuerzas en presencia y las formas de antagonismos. Al actualizarse nuevas formas de embates clasistas, la clase dominante incorpora, como efecto de contratendencia, nuevas formas de intervenciones de carácter técnica, política, económica. La clase dominante, con el objetivo de diferenciar las tendencias de las contratendencias, debe controlar, accionar y desviar la contratendencia -en respuesta a la caída de tasa de lucro- para así recomponer, restaurar la unidad de fuerzas productivas y 
dispositivos de hegemonía. La situación de crisis orgánica abre períodos de grandes alteraciones históricas como, por ejemplo, el pasaje de un régimen de acumulación para otro como ocurrió en el caso del fascismo en Italia y del fordismo en Estados Unidos. En este sentido, se torna necesario reconstituir aquello que da regularidad y estabilidad a los movimientos de la estructura, comprenda-se, en este punto, las estructuras fundamentales de la propia acumulación capitalista. Aqui entran en juego formas específicas de revolución pasiva que se cristalizan en estratégias de largo plazo.

Las estrategias de largo plazo que las clases dominantes erigen se objetiva en abrir posibilidades (de base real) de salida de la situación de crisis orgánica y, en este sentido, transferir la propia guerra de posición de las clases dominantes para las clases subalternas con el fin de aniquilar toda tentativa -por parte de las masas- de construcción de un bloque social, intelectual y moral (fundamento de toda hegemonía), imponiendo la reproducción del mismo modo de producción (en este caso, modo de producción capitalista) e inhibiendo el aspecto ético-político obligando, de esta manera, al conjunto de las clases subalternas, a retroceder hacia el terreno económico corporativo.

Un trazo fundamental de la teoria gramsciana de la hegemonía se construye a través del Análisis de Situación y Correlaciones de Fuerzas. Este conjunto de notas constituye la reflexión específica del problema de construcción de la hegemonía. Asimismo, estas notas brindan elementos fundamentales para comprender la relación entre revolución pasiva guerra de posición en la realización de la hegemonía.

En términos analíticos, la correlación de fuerzas se da en tres momentos: 1) La clase existe objetivamente. En la base del grado de desarrollo de las fuerzas materiales de producción se estructuran los agrupamientos sociales, cada uno de los cuales representa una función y ocupa una posición determinada en la producción. Esto permite verificar si en la sociedad existen las condiciones necesarias y suficientes para su 
transformación; permite controlar el grado de realismo y de viabilidad de las diversas ideologías que ésta generó durante su transcurso. 2) El momento siguiente es el de la relación de fuerzas políticas. Las clases viven un proceso económico-corporativo, en que están limitadas a sus intenteses específicos. A su vez, este momento tiene varios grados que corresponden a los diversos momentos de la conciencia colectiva. El primero, es el momento económico-corporativo, donde el proceso de identificación se produce a nivel de corporación y no de clase. Un segundo momento es aquel donde la clase, aunque no se coloque todavia como objetivo la cuestión estatal, logra tener consciencia e identidad de clase. Un tercer momento, especificamente político es aquel en el que se adquiere la consciencia de que los propios intereses corporativos, en su desarrollo actual y futuro, superan el círculo corporativo, de grupo meramente económico, y pueden y deben tornarse los intereses de otros grupos subalternos. Esta pasa a ser la fase más abiertamente política segun Gramsci- que señala el pasaje, de forma clara, de la estructura para la esfera de las superestructuras complejas; es la fase en que las ideologías germinadas anteriormente se transforman en 'partido', entran en choque y luchan hasta que una de éstas, o por lo menos una combinación de éstas, tiende a prevalecer e a imponerse, determinando no sólo la unicidad de los fines económicos y políticos sino también la unidad intelectual y moral. 3) El tercer momento es el da la relación de las fuerzas militares. También en este momento se pueden distinguir dos grados: el militar, o técnico militar y el grado denominado político militar. Este momento se manifiesta, fundamentalmente, en dos situaciones bien diferenciadas: el de la creación de un nuevo bloque histórico (la Revolución Francesa, la Revolución Rusa) y el de emancipación nacional. ${ }^{2}$

2 Para profundizar la cuestión de Análisis de Situación y Correlaciones de Fuerzas consultar Gramsci, 1976 (MPE): 43-63 
Gramsci colocará posteriormente que "el desarrollo histórico oscila continuamente entre el primer y el tercer momento, con la mediación del segundo" (1976, p.51). En este sentido, "la realización de un nuevo bloque histórico, de una begemonia, es la consecución de una posibilidad inscripta en la totalidad social' (Dias, 1996b, p.14).

El concepto de crisis orgánica es clave para reconstruir el concepto 'binomio' revolución pasiva - guerra de posición.

Con el objeto de intentar aprehender el concepto de revolución passiva, de modo general, podríamos decir, a partir de un primer abordaje, que éste expresa una estrategia política de transición.

Por otra parte, cabe aclarar, que este concepto fue adoptado por Vincenzo Cuoco haciendo referencia a los aconteciminetos italianos de 1799, focalizado, especificamente, al primer período del Risorgimento. Teniendo en cuenta que el Risorgimento constituye el momento inicial de consolidación del capitalismo italiano, Gramsci incorpora la categoria revolución pasiva como un recurso teórico-metodológico con el objetivo de analizar las particularidades del proceso de conformación de la cuestión nacional en Italia.

Tanto en sus notas sobre "Análisis de situación, correlaciones de fuerza" como en el concepto de revolución passiva, Gramsci establece una relación com el prefácio de 1859 de la "Introducción a la Crítica de la Economía Política" de Marx:

'El concepto de 'revolución pasiva' se deduce rigurosamente de los dos principios fundamentales de ciencia politica: 1) ninguna formación social desaparece mientras las fuerzas productivas que en esta se desarrollaron encuentren lugar para un ulterior movimiento progresista; 2) la sociedad no asume compromisos para cuya solución todavia no tengan surgido las condiciones necesarias, etc." (1976, p.75) 
Por lo tanto, estos dos criterios de ciencia política formulados por Marx en el Prefacio de 1859 constituyen el fundamento y el recurso teórico-metodológico de la revolución pasiva.

Una primer definición que Gramsci aborda de revolución pasiva es la siguiente:

"Se puede aplicar al concepto de revolución pasiva (documentandose en el Risorgimento italiano) el criterio interpretativo de las modificaciones moleculares que, en realidad, modifican progresivamente la composición precedente de las fuerzas $y$, por lo tanto, se transforman en matriz de novas modificaciones" $(1976$, p.77).

En este sentido, el transformismo es concebido por Gramsci como una de las formas históricas de la revolución pasiva.

Otro aspecto del abordaje de Gramsci al respecto es el de la dialéctica innovación - conservación como dinámica del desarrollo histórico, donde lo fundamental es, más allá de los cambios que se incorporen, que los elementos de la tesis son siempre conservados. En este sentido, la innovación conserva el pasado al superarlo.

"La fuerza innovadora desde el momento en que no es un becho arbitrario, no puede dejar de estar ya inmanente en el pasado, no puede dejar de ser, en cierto sentido, el pasado, un elemento del pasado, lo que del pasado está vivo y en desarrollo; ésta es conservación - innovación, contiene en si todo el pasado digno de desarrollarse y perpetuarse."(Gramsci, 1995, p.251)

Asimismo, la revolución pasiva es entendida por Gramsci como dialéctica revolución - restauración:

"... en la oposición dialéctica sólo la tesis desarrolla, en realidad, todas sus posibilidades de lucha, hasta atraer para si los llamados representantes de la antitesis: exactamente en esta formulación 
consiste la revolución pasiva o revolución-restauración."(1976, p.7778)

Por lo tanto, lo precedente sería el reflejo de aquello que Gramsci llamó de "dialéctica mutilada". De aqui deriva, en gran medida, la expresa oposición de Gramsci al reformismo conservador de Croce. Gramsci va a plantear que Croce, opera una mutilación en el método hegeliano porque su "dialéctica" está fundada en una "dialéctica de los distintos"y no en una "dialéctica de los contrarios". En realidade esto no seria dialéctica en el sentido que la tesis no es superada y, por lo tanto, la sintesis, al no ser fundada en una "dialéctica de los opuestos" conserva los elementos fundamentales de la tesis que no se ha dejado superar por la antitesis.

La revolución passiva, es, por lo tanto, la cristalización de una estrategia restauracionista y reformista en la que las fuerzas antagónicas son absorvidas por el orden hegemónico. Esta estrategia se traduce en el principio "cambiar para que nada cambie", o, en otros términos, "revolución sin revolución". De esta manera, la revolución pasiva revela la inexistencia de cualquier iniciativa popular unitaria y es, en este sentido, una respuesta efectiva y neutralizadora al proceso de lucha de clases.

Por otra parte, la relación que Gramsci establece entre revolución pasiva y hegemonía es mediado por el concepto clave guerra de posición. Así como en la concepción gramsciana la revolución pasiva determina las formas de un proceso de transformación cristalizado en un proceso de carácter reformista y antiradical, la guerra de posición es lo que determina las formas de confrontación de clase en relación a este proceso transformativo. En este sentido, la guerra de posición se materializa como revolución pasiva para las clases dominantes.

La revolución pasiva traslada sus formas de guerra de posición a las masas; lleva una base del consentimiento y de adhesión ideológica de las masas a las clases dominantes. Las clases subalternas, son así 
orientadas para el terreno económico-corporativo suprimiento, como consecuencia, el elemento ético-político de la fuerza antagónica, elemento vital para la construcción de la hegemonía. Se produce, así, una nueva subalternidad de las masas. La guerra de posición asume, por lo tanto, la forma de revolución pasiva para la clase dominante y de contrarevolución para las clases subalternas.

Por lo tanto, podemos pensar, en principio, el proceso de revolución pasiva como - en el caso del Resurgimento italiano- via antijacobina de transición para el modo de producción capitalista. Por otra parte, como proceso de transición, esta vez en el interior del modo de producción capitalista -objetivado en dos individualizaciones-: el régimen fascista y el régimen fordista. En este sentido, para el caso de la transición en el interior del modo de producción capitalista tendríamos una identificación entre los conceptos de revolución pasiva y de hegemonía o, en otros términos, la hegemonía pasaria a ser "aparente" ya que estaría tomando, en realidad, la forma de revolución pasiva.

La hegemonía es vista por Gramsci como la construcción de un proyecto de clase. Es concebida, asimismo, como una reforma intelectual y moral. La reforma intelectual y moral pasa, necesariamente, por una crítica ao economicismo y a todo tipo de reduccionismo. Es la constitución de una nueva personalidad histórica. Toda reforma intelectual y moral debe, también estar acompañada de un nuevo programa económico. Por lo tanto, el concepto gramsciano de hegemonía está revestido de un gran amplitud, es decir, la hegemonía opera no apenas sobre la estructura económica y sobre la organización política de la sociedad, sino también, sobre los modos de pensar, de hacer y de conocer, sobre las orientaciones ideológicas que mueven a los individuos. La hegemonía es la construcción de una nueva civilización cimentada en una nueva racionalidad.

Una cuestión crucial, es que existe una estrecha relación entre la capacidad de construcción de una visión de mundo y la realización de la 
hegemonía. En los términos de Fernandes Dias (1996b, p.10), "/a capacidad que una clase tenga de construir su hegemonia, depende de su posibilidad de elaborar una visión de mundo propia, autónoma."

Para llegar a explicitar lo que es la hegemonía, Gramsci parte de la afirmación de que todo ser humano es filósofo. Esa filosofía peculiar a todos los seres humanos está en el propio lenguaje, en el sentido común, en el buen sentido y en todo el sistema de creencias, opiniones, en los modos de ver y de actuar en la vida. Todo ser humano participa de una determinada concepción del mundo, aunque sea de manera inconsciente y acrítica, y es en el propio lenguaje donde se cristaliza esta concepción del mundo inherente a cada uno. Todavía, es a partir del propio lenguaje en donde es posible percibir el grado de complejidad de su concepción del mundo. Así, por la propia concepción, el ser humano es conformista de algún conformismo. El problema sería cuál es el tipo histórico de conformismo y de hombre-masa del que el ser humano hace parte. En todo ser humano está presente una consciencia impuesta por el ambiente en que vive. Gramsci se preguntará si es preferible "pensar" sin tener consciencia crítica de esto, de uma manera desagregada y ocasional, es decir, participar de una concepción del mundo "impuesta" mecanicamente por el ambiente exterior a partir de los varios grupos en los cuales todos están automaticamente comprometidos desde su entrada en el mundo consciente o si es preferible elaborar la propia concepción del mundo de una manera crítica y consciente y, por lo tanto, en relación con este trabajo del propio cerebro, escoger la propia esfera de actividad, participar activamente en la producción de la historia del mundo, ser el guia de sí mismo y no aceptar del exterior, pasiva y servilmente, la marca de la propia personalidad (1995, p.12).

Entonces, criticar, problematizar, desnaturalizar la propia concepción del mundo significa hacerla unitaria y coherente y elevarla hasta el punto alcanzado por el pensamiento social más desarrollado. Significa, asimismo, criticar toda filosofia hasta hoy existente. En este 
sentido, no podemos tener una concepción del mundo criticamente coherente y unitaria sin la consciencia de nuestra historicidad, sin la consciencia de que ésta puede entrar en contradicción con otras concepciones del mundo.

Cabe, en este punto preguntarnos sobre la función de los intelectuales y su misión histórica en el processo de construcción de la hegemonía.

Para Gramsci, cada clase fundamental tiene sus propios intelectuales. $Y$ va a abordar esta cuestión a partir de su ser social, del lugar que tienen los intelectuales en las relaciones de producción. Los intelectuales se sitúan en un lugar definido en la división del trabajo, ejercen funciones. A su vez, Gramsci distingue el hecho de ser intelectual del hecho de ejercer la función de intelectual.

Una función clave del intelectual sería la de desmistificar el sentido común y colocar dosis de buen sentido, a través de un ejercicio de crítica al sentido común e intentado introducir una visión del mundo más apropiada a la consciencia de las clases subalternas. Un aspecto fundamental del sentido común es el de ser una concepción disgregada, incoherente. Este oculta el ejercicio de dominación de los poderes hegemónicos. Al contrario, el buen sentido seria una filosofía homogénea, coherente, sistemática que elabora un grupo social organizado contra el sentido común.

El problema fundamental de toda concepción del mundo es el de conservar la unidad ideológica de todo el bloque social, el cual está cimentado y unificado justamente, por aquella determinada ideología. Ideología, es entendida por Gramsci, como una determinada concepción del mundo y de la vida que se manifiesta implícitamente en el arte, en el derecho, en la actividad económica, en fin, en todas las esferas de la vida individual y colectiva. Gramsci va a llamar la atención, apuntando al problema desafiante de la construcción de la hegemonía, que una de las mayores debilidades de las filosofías de carácter inmanentistas en 
general, consiste precisamente, en no tener la capacidad de crear una unidad ideológica entre lo superior y lo inferior, es decir, entre los "simples" y los "intelectuales". Si los intelectuales se tornaran los intelectuales orgánicos de las masas, y en este sentido, se hubieran tornado coherente los principios y los problemas que el pueblo colocaba con su actividad práctica, debería verificarse entre los intelectuales y los simples la misma unidad que debe existir entre teoría y práctica, posibilitando así, la construcción de un bloque social y cultural plasmado en una solidez y organicidad cultural y de pensamiento. Por eso, para Gramsci, elaborar un movimiento filosófico sistemático, renovado, unitario y coherente sólo es posible con el permanente contacto cultural com los "simples". En el contacto intelectuales y masa se encuentra la fuente de los problemas que deben ser resueltos para que esta "filosofía" no quede restringida a una minoría de grupos intelectuales privilegiados. A partir de este contacto, por lo tanto, es que una filosofía tiene condiciones de tornarse histórica depurandose de los elementos intelectualistas de naturaleza individual y se transforma en "vida", tanto para los intelectuales, como para las masas, y deja de tener un carácter arbitrario para transformarse en una filosofía orgánica.

En este sentido, el rol clave de la filosofía de la praxis, lejos de mantener los "simples" en su filosofía primitiva del sentido común, busca, al contrario, conducir permanentemente a las masas a una concepción de vida superior. El hecho de que la filosofía de la praxis enfatice en el contacto intelectuales-masa radica fundamentalmente lejos de limitar la actividad científica - en forjar un bloque intelectual y moral que posibilite un proceso de crecimiento intelectual íntegro a nivel de masa y no apenas de pequeños grupos intelectuales. Por eso, la hegemonía, es fundamentalmente, una relación pedagógica por ser, justamente, una experiencia colectiva de emancipación.

Todo el proceso de formación crítica, y por lo tanto, de intervención activa y consciente en el desarrollo histórico es producto de 
un proceso social, de una formación de carácter político-ideológica, en la cual, de acuerdo con Gramsci, el partido tiene un papel esencial.

Gramsci va abordar la cuestión de la hegemonía en los siguientes términos:

'La comprensión critica de si mismo es obtenida, por lo tanto, a través de una lucha de 'begemonias' políticas, de direcciones contrastantes, primero en el campo de la ética, después en el de la política, alcanzando, finalmente, una elaboración superior de la propia concepción de lo real. La consciencia de bacer parte de una determinada fuerza hegemónica (es decir, la consciencia política) es la primera fase de una ulterior e progresiva autoconsciencia, en la cual teoria y práctica finalmente se unifican. Por lo tanto, también la unidad de teoria y práctica no es un becho mecánico, sino un devenir bistórico, que tiene su fase elementar y primitiva en 'el sentido de 'distinción', de 'separación', de independencia apenas instintiva, $y$ avanza hasta la posesión realy completa de una concepción del mundo coberente y unitaria. Es por eso que se debe llamar la atención para el becho de que el desarrollo político del concepto de begemonía representa - aparte del progreso político-práctico - un grande progreso filosófico, ya que implica y supone necesariamente una unidad intelectual y una ética adecuadas a una concepición de lo real que superó el sentido común y se tornó crítica, aunque dentro de limites todavia estrictos" (1995, p.21).

A partir de los elementos colocados precedentemente, podemos inferir que hegemonía conforme la teoría gramsciana no implica mero dominio ideológico o mayoría eventual (apropiandonos de los términos colocados por Dias, 1996). Hegemonía significa crítica real de una filosofía.

Según las formulaciones de Gramsci presentes en los Cuadernos de la Cárcel, y conforme a los elementos analizados más arriba, es 
posible vislumbrar que una clase fundamental, para convertirse en hegemónica, se puede valer, principalmente, de dos estrategias: una, tal como vimos, el transformismo/reformismo, o, dicho en otros términos la estrategia de revolución-restauración; innovación-conservación. La otra, es la hegemonía propiamente dicha. En la primera estrategia estariamos ante un proceso de "subordinación ideológica" o "consentimiento pasivo" y, por lo tanto, lejos de ser la construcción de una verdadera hegemonía sería una estrategia de revolución pasivaguerra de posición en la medida en que las clases subalternas son absorbidas al proyecto de la clase dominante. En este caso, la hegemonía tomaria la forma de revolución pasiva. La segunda estrategia, está fundada en el consentimiento activo, es decir, en una voluntad colectiva y popular. Esta es producto de una concepción del mundo que logró ser unitaria, coherente y sistemática, en la medida en que se realizó una fusión de intereses entre "intelectuales" y "masa".

\section{AMERICANISMO Y FORDISMO EN LA CRÍTICA DE GRAMSCI: HEGEMONÍA O REVOLUCIÓN PASIVA?}

Este segundo foco de análisis, estrictamente ligado a procesos reales, más específicamente, a la íntima relación entre procesos productivos y procesos de reproducción social y cultural, Gramsci lo interpreta todavia como parte integrante y constitutiva de las formas de revolución pasiva; como formas de actualización de la racionalidad burguesa. Este conjunto de problemas son abordados en los textos relativos a Americanismo y Fordismo donde el eje de estas notas está puesto en el cuestionamiento de la desigualdad del desarrollo del capitalismo (relación Europa - Estados Unidos de América) y en el surgimento de nuevas formas de estructuración del sistema capitalista de producción y de consumo. 
Gramsci desenmascara la dimensión multifacética que compromete el fordismo como una forma clara de capitalismo que está en la integralidad y en la cotidianeidad de la vida americana. En este sentido, nos proponemos indagar cómo Gramsci percibió el fenómeno de este binomio inseparable, 'americanismo', como modo de organización de las relaciones sociales, humanas, culturales; 'fordismo', como forma particularmente desarrollada de organización del trabajo en el contexto de la producción inmediata (entendido como taylorismo, producción en serie, línea de montaje, trabajo parcelado, etc.)

En el contexto de este dispositivo instrumental de la "filosofía de la praxis" es que Gramsci aborda el fenómeno de "Americanismo y Fordismo", con el objetivo permanente de recuperar la intervención estratégica del marxismo. Y lo va a abordar llamando la atención con respecto a cuáles serian las condiciones en que se podría operar la hegemonia proletaria, y, al mismo tiempo, cómo se conduciría la ampliación del movimiento comunista en el plano internacional, dada la actual correlación de fuerzas delineadas por aquellos cambios (Souza, 1992, p.3).

Gramsci elabora estas notas en torno a dos grandes problemáticas de carácter estructurales: por un lado, la emergencia de un nuevo padrón de relaciones industriales y de acumulación en el contexto del capitalismo; por otro lado, las necesidades abiertas por la Revolución de Octubre y la construcción del socialismo en Europa del Este (Souza, 1992, p.3).

Gramsci va a problematizar estas nuevas estrategias de acumulación del capital a partir del establecimiento de los métodos de control del trabajo taylor/fordista. Así, va a explicitar que el americanismo y fordismo derivan de la necesidad inmanente de organizar una economía programática.Algunas de las cuestiones que se propone problematizar en este conjunto de notas son los siguientes:

sustitución de la actual camada plutocrática por un nuevo mecanismo de acumulación y distribución del capital financiero basado directamente en la producción industrial; el problema 
sexual; ver si el americanismo puede determinar un desarrollo gradual del tipo, ya examinado, de las "revoluciones pasivas" características del siglo pasado, o si, al contrario, representa apenas la acumulación molecular de elementos destinados a produzir una "explosión", una transformación de tipo francés; problema de la racionalización de la composición demográfica europea; ver si el desarrollo debe tener su punto de partida en el interior del mundo de la industria y de la produción o si se puede verificar a partir del exterior, a través de la construcción cautelosa y maciza de una estructura juridica formal que oriente de afuera el proceso de desarrollo necesario del dispositivo de la producción; problema de los llamados "altos salários" pagados por la industria fordizada y racionalizada; el fordismo como punto extremo del proceso de tentativas sucesivas de la industria para superar la ley tendencial de la caída de la tasa de lucro; el psicoanálisis (su gran difusión durante la posguerra) como expresión de la creciente coerción moral ejercida por el aparato estatal y social sobre los individuos y de las crisis de depresión que esta coerción determina (Gramsci, 1976, p.375 - 376).

Segundo Tude de Souza (1992, p.5), lo fundamental para Gramsci, fue comprender las estratégias de largo plazo emprendidas por las clases dominantes italiana y norteamericana. Estrategias que objetivabam recomponer la unidad entre las relaciones sociales de producción, las nuevas exigencias de acumulación del capital - entonces francamente comprometidas por la caída tendencial de la tasa de lucro ${ }^{3}$ - y sus dispositivos de hegemonía. En este sentido, el fenómeno de

${ }^{3}$ A partir de los estudios de Marx en "E.l Capital" sobre la "Caída tendencial de la tasa de lucro" Gramsci reformula su hipótesis explicitando que el taylorismo y el fordismo, como métodos de producción y de trabajo, son tentativas progresivas que buscan superar esa ley tendencial, a través de la multiplicación de las variables en las condiciones del aumento progresivo del capital constante. Para mayores detalles, consultar GRAMSCI, 1995 CDH: 246 -247) 
americanismo y fordismo pueden ser interpretados como una respuesta capitalista de contratendencia a la caída tendencial de la tasa de lucro, como la más orgánica e intencional salida capitalista de la Grande Depresión de los años 30, de sistemática intervención en el proceso de producción inmediata, en fin, como un proceso de desarrollo de la hegemonía a partir directamente de la fábrica. En este contexto de crisis orgánica en Occidente, la clase dominante objetiva reconducir al movimiento operario como también al conjunto de las clases subalternas, al terreno de las luchas económico-corporativas.

Por lo tanto, el americanismo y fordismo son entendido por Gramsci como una reformulación del orden político, económico y social (instalada en el interior del modo de producción capitalista) a partir de decisiones estatales y corporativas. Estas nuevas estrategias son implementadas, en principio, por sectores del patronato industrial para sanear los conflictos económicos y culturales que germinaron en la sociedad americana en el período de la posguerra. Se crea, así, en primer lugar, un nuevo modelo de relaciones industriales que tiene por objetivo reconstituir el trabajador colectivo conforme a las nuevas exigencias de la racionalidad productiva y sus demandas por control, eficiencia $y$ racionalidad. Gramsci atribuye a los conceptos de americanismo y fordismo un carácter analitico y estratégico (Souza, 1992) para designar determinadas situaciones en que la clase dominante organiza toda la vida nacional (social, cultural) construyendo en torno del Estado un sistema de dispositivos (privados, semipúblicos y públicos) que constituyen las diversas proyecciones de la función de dirección politica en la sociedad civil (Gramsci, 1976).

Por otra parte, el conjunto de movimientos iniciados por Ford con respecto a la línea de montaje van a ser juzgados por Gramsci como transformaciones que todavía están en su fase inicial y como "modificaciones moleculares", de carácter progresivo, que se originan a partir del desarrollo de las fuerzas productivas, en el contexto capitalista americano. En las palabras de Gramsci: 
'Mas en realidad, no se trata de novedades originales, se trata solamente de la fase más reciente de un largo proceso que comenzó con el propio nacimiento del industrialismo, fase que apenas es más intensa de que las precedentes y se manifiesta bajo formas más brutales, pero que también será superada con la creación de un nuevo nexo psico-físico de un tipo diferente de los precentes e, indudablemente, superior. Se verificará, inevitablemente, una selección forzada, una parte de la vieja clase trabajadora será impiadosamente eliminada del mundo del trabajo y tal vez del mundo tout court." (Gramsci, 1976, p.397)

El americanismo fue visualizado por Gramsci como revolución pasiva en el sentjdo que hubo una restauración/reestructuración del capital con el objetivo de contener el movimiento operário, para así mantener el dominio de la clase dominante, es decir, el dominio del capital. La clase operaria es incorporada al proyecto de la clase dominante a través de un conjunto de transformaciones, sea en lo cotidiano de las clases subalternas, sea en la reformulación de los mecanismos de representación sindical (reformulación del sindicalismo a través de la quiebra de los sindicatos de ofícios) hasta lograr que el proletariado piense en la lógica del capital.

Americanismo y fordismo se constituye en una 'hegemonía' sobre la base de la restauración - reorganización de la producción. En este sentido, es una cristalización de la estrategia de 'guerra de posición'. Si bien hubo un conjunto de reformulaciones y transformaciones producto de la intervención del Estado y del papel de los monopolios, es preciso dejar claro que la 'síntesis' de ésto no fue un nuevo 'automatismo' ni tampoco un nuevo 'mercado determinado'. La nueva dinámica instaurado por el americanismo no hizo más que reproduzir, con algún grado de transformismo, formas preexistentes de las relaciones de las fuerzas sociales. 
El fenómeno de americanismo y fordismo fue producto de un proceso de racionalización que tuvo como objetivo intervenir para modificar la relación existente entre el conjunto de las camadas sociales con el proceso de producción, reformular y tornar más sana la composición demográfica, redefinir los términos de la división internacional del trabajo, optando por la más lucrativa de las posibilidades que esta división puede ofrecer; en síntesis, era preciso, definitivamente, la formación de una nueva clase dirigente (De Felice, 1978).

Una de las tesis que va a desarrollar Gramsci en este conjunto de textos es que "la racionalización determinó la necesidad de elaborar un nuevo tipo bumano conforme un nuevo tipo de trabajo y de producción."(Gramsci, 1976, p. 382). Con la fuerza de la persuación, el fordismo crea un nuevo tipo de trabajador, fundamentado en las condiciones políticas, económicas y culturales existentes al interior de la vasta formación de la sociedad americana. Es ésta justamente, la hipótesis que va a atravesar "americanismo y fordismo" vislumbrando este fenómeno como una nueva "filosofia" - a partir de los nuevos métodos de trabajo - que penetra las múltiples dimensiones de la vida americana. Así, el americanismo reformula, no apenas las prácticas dentro de la fábrica, sino también reformula las condiciones de existencia de los sujetos comprometidos en este contexto.

Racionalizar la producción significa racionalizar el modo de vivir, es decir, disciplinar el cuerpo e instalar la vida de la fábrica al conjunto de la sociedad. No cabe duda, que el fin último de este conjunto de reformulaciones en la estructura del proceso productivo es la propia valorización del capital. Tal es la razón por la cual industrias como Ford se interesaban por las "relaciones sexuales de sus operarios" y por la "posición de sus familias". Dirá Gramsci: 
'La apariencia de 'puritanismo' asumido por este interés (como en el caso del probibicionismo) no debe llevar a evaluaciones erradas; la verdad es que no es posible desarrollar el nuevo tipo de hombre solicitado por la racionalización de la producción y del trabajo, mientras el instinto sexual no sea absolutamente reglamentado, no sea también éste, racionalizado.'(1976, p. 392) 'Los nuevos métodos exigen una rigida disciplina de los instintos sexuales (del sistema nervioso), un reforzamiento de la 'familia' en sentido amplio (...), la reglamentación y la estabilidad de las relaciones sexuales." (1976, p. 394-395)

Así, el conjunto de "iniciativas puritanas" propugnadas primero por Taylor, y posteriormente por Ford, va a tener como finalidad conservar fuera del ámbito del trabajo, un determinado equilibrio psicofísico que impida el colapso fisiológico del trabajador, exprimido por los nuevos métodos de producción. Gramsci va a hablar en términos de creación de un nuevo nexo psico-físico. A este respecto, Fernandes Dias (1996b, p.66) dirá: "Fabricar el nuevo trabajador supone la creación de un nuevo hombre, es decir, la destrucción activa de una personalidad bistórica". Es, asimismo, neutralizar todo el potencial emancipatorio que traen las clases subalternas.

Según Fernandes Dias (1996b, p.66), la experiencia americana taylor/fordista profundizó considerablemente formas preexistentes de subordinación del trabajo al capital y se instauró con el propósito de quebrar el poder de resistencia del conjunto de trabajadores. En este sentido, la destrucción de los sindicatos de oficios, que era la expresión corporativa de la propiedad de los ofícios calificados, era una necesidad vital para el capitalismo americano.

$\mathrm{El}$ fordismo es concebido por Gramsci como un arma política habilmente usada por la clase dirigente para neutralizar y anular las organizaciones de combate de la clase operaria. Se contruye un nuevo perfil de trabajador colectivo a partir del cual se erige una nueva clase 
operaria y una nueva clase media. Esto trae como consecuencia una nueva configuración de las relaciones entre intelectuales y masa en el proceso de construcción de la hegemonía burguesa.

Todo modo de producción precisa de un aparato ideológico que legitime sus formas de proceder. Gramsci va a ser explícito en este aspecto cuando plantea que "la americanización exige un determinado ambiente, una determinada estructura social (o la voluntad de decidirla y de crearla) y un determinado tipo de Estado." (1976, p.388). De esta manera, es importante resaltar la previsión de Gramsci con repecto de la manera como el fordismo dependía, fundamentalmente, de la asunción de los estados nacionales en lo concerniente a su rol de reglamentación social. Gramsci va a agregar: "El Estado es el Estado liberal, no en el sentido de la efectiva libertad política, sino en el sentido más fundamental de la libre iniciativa y del individualismo económico que alcanza a través de medios propios, como 'sociedad civil, a través del propio desarrollo bistórico, el régimen de la concentración industrial y del monopolio." (1976, p.388)

El fordismo, conforme plantea Gramsci, fue aquella forma de hegemonía que supo combinar coerción (liquidación del sindicalismo operario de base territorial) y consenso (altos salarios, beneficios sociales diversos, propaganda ideológica y politica habilisimas) para finalmente basar toda la vida nacional en la producción:

'La adaptación a los nuevos métodos de producción y de trabajo no se puede verificar a través de la coacción social... La coerción debe ser sabiamente combinada con la persuación y el consentimiento, y esto puede ser obtenido en las formas adecuadas de una determinada sociedad, por una mayor retribución que permita un determinado nivel de vida, capaz de mantener y reintegrar las fuerzas desgastadas por el nuevo tipo de trabajo." (1976, p.404-405).

Gramsci va a resaltar que la industria americana que paga altos salarios disfruta del monopolio que le fue proporcionado por la primacía 
en la implantación de los nuevos métodos de trabajo. Por lo tanto, a los lucros de monopolio corresponden los salarios de monopolio. Pero el monopolio será necesariamente, primero limitado y, luego eliminado por la difusión de los nuevos métodos en su integridad $\mathrm{y}$, como consecuencia, los lucros elevados y los altos salarios desaparecerán.

Americanismo y fordismo son concebidos por Gramsci como revolución pasiva y como modernización conservadora. Este recrea una 'nueva racionalidad' sobre la matriz de la 'vieja racionalidad'.

Finalmente, Gramsci va a plantear el problema en términos de si existiría en América una nueva civilización, una nueva cultura. Como respuesta a este asunto él va a recalcar que el fenómeno de americanismo y fordismo no puede ser considerado como una nueva civilización por el simple hecho de que nada cambió radicalmente en la estrucutura de las relaciones entre los grupos fundamentales. Americanismo y fordismo no llega a ser mas que un prolongamiento orgánico y una intensificación de la civilización europea, que adquirió una nueva piel en el contexto americano. Este fenómeno, por lo tanto, fue concebido por Gramsci, como una de las experiencias más claras y elevadas de revolución pasiva.

\section{A MANERA DE CONCLUSIÓN: REESTRUCTURACIÓN PRODUCTIVA Y PASIVIZACIÓN}

El período de transición 1960 - 1970 fue revelando un conjunto de elementos que nos permiten caracterizar el momento actual del capitalismo como un período de crisis orgánica en sentido gramsciano. Durante el transcurso de las dos últimas décadas, la crisis del capitalismo como sistema mundial de producción, ha engendrado profundas transformaciones tanto en la esfera de la producción inmediata como en la esfera de la reproducción social. Así, en el capitalismo contemporáneo, se han perfilado cambios en las formas de organización estatal y 
reformulaciones del conjunto de las estrategias políticas, económicas y sociales.

La crisis orgánica contemporánea es producto de un proceso de agotamiento de los fundamentos económicos, sociales, políticos y filosóficos del consentimiento y de la integración de las clases subalternas al orden 'hegemónico' característico del período de possegunda guerra hasta los años 70. La compleja crisis actual que se inaugura oficialmente como "crisis energética" en mediados de los años 70 , rompe con el compromiso Welfare State. Como salida a la crisis, el capitalismo contemporáneo busca liberarse del conjunto de conquistas sociales que fuera obligado a aceptar como medida de contratendencia frente al avance de los movimientos que tenían como horizonte la alternativa socialista. Así el capitalismo redefine, actualmente, el conjunto. de las relaciones clasistas.

El fin del llamado "socialismo real" fue un determinante clave en esta crisis. Para el conjunto de las clases trabajadoras, la derrocada de los países del Este Europeo significó el fin de una sociabilidad alternativa y de una referencia classista internacional. El capitalismo 'triunfante' visto desde el sentido común - se está tomando la atribución de introducir cambios en el sistema sin importarle el costo de esas transformaciones. Políticas de ajustes en las áres de salud, educación, asistencia social, así como también recorte en las políticas que fueron producto de conquistas históricas reivindicada con sangre por el conjunto de las clases trabajadoras. Las políticas de corte neoliberal y la "reestructuración productiva" en curso constituyen las estrategias fundamentales de esta fase del capitalismo lo cual se cristaliza muy claramente en una estrategia de recomposición/restauración de la vieja institucionalidad. La creciente intervención del gran capital se realiza actualmente de manera directa o indirecta por medio de los intelectuales orgánicos colectivo del sistema como la OECD, el FMI y el Banco Mundial. El Estado se convierte en un 'Estado Mínimo' mas 'mínimo 
necesario' para la progresiva conformación del 'mercado máximo'. El reformismo es, una vez más, el trazo relevante de la época en que vivimos.

Dirá Braga (1997a, p.175) en obra donde hace un análisis de la crisis contemporánea:

'La reaccioion del capital asume un aspecto esencialmente 'restauracionista'. La principal tarea de las clases dominantes pasa a ser la de erigir contratendencias para retardar las consecuencias de la tendencia a la caída de la tasa de lucros. En ese proceso, se debe intensificar los métodos de trabajo, modificar las formas de vida operaria, multiplicar el desarrollo de las fuerzas productivas, $y$ principalmente, engendrar las bases politicas y sociales de una iniciativa que permita a las clases dominantes presentar sus intereses particulares como universales, es decir, válidos para todas las clases. La capacidad hegemónica, politica y cultural de la burguesia radica en su estrategia de absorber las bandera de lucha de los adversarios bistóricos, integrando a su propia racionalidad importantes elementos de la concepción y necesidades del nuevo protagonista, asimilando elementos de su programa y parte de sus intelectuales, via el proceso de 'transformismo.",

Varios son los autores ${ }^{4}$ que están procurando analizar un nuevo automatismo para el capitalismo contemporáneo en crisis. Para estos autores, el capitalismo estaría engendrando a partir de su proceso de crisis y reestructuración, las bases materiales y sociales viabilizadoras de

\footnotetext{
"Principalmente Aglietta "Regulación y crisis del capitalistmo" Siglo XXI Madrid, 1979; Piore y Sabel "The Second Industrial Divide" Basic Books New Yord, 1984; Hirst y Zeitlin "Reversing Industrial decline?"St. Martin Press. New Yor, 1989; Kern y Schumann "El fin de la división del trabajo", Ministerio de Trabajo y Seguridad Social. Madrid, 1989, (Kern y Shumann analizan esta cuestión más estrictamente ligada a la esfera de la producción inmediata), entre otros.
} 
un "nuevo padrón de acumulación". Estaríamos, por lo tanto, frente a significativas transformaciones tanto en la esfera productiva como en la reproductiva, cuyos componentes serian: nuevas industrias de sustentación basadas en nuevas tecnologías (automatización, robótica, informática, microelectrónica, teletransmisión); un nivel mayor de racionalización de los procesos productivos asi como también nuevas formas de gestión, de organización y de control del proceso de trabajo; nuevos padrones de demanda y de consumo colectivo. Estas serían las tendencias más claras de recomposición del orden hegemónico cristalizado en las formas de dominación y subalternidad renovadas - de la actual coyuntura.

Los adeptos a la reestructuración productiva enfatizan un nuevo tipo de trabajo creativo y calificado que prescinde de la concentración en la fábrica. Un trabajo que es hecho frente a la computadora, artesanal y de calidad. Así el trabajador tendría la impresión de mayor autonomía y libertad. Este trabajador es considerado un "artesano electrónico" y por el hecho de desempeñarse en su local de trabajo tendría la sensación de ser un "ciudadano en el mundo del trabajo". Se trataría, por lo tanto, de un trabajador polivalente, preparado.a para dominar la totalidad de su oficio y para tomar decisiones en lo cotidiano del proceso productivo. Se afirma, consecuentemente, que se recuperaría la subjetividad del trabajador y se 'des-construiría', progresivamente, el trabajador mecanicista y repetidor de gestos monótonos. A partir de la generalización de algunas experiencias bien sucedidas en lo concerniente a los nuevos métodos de trabajo, va ganando relevancia un discurso que propugna que acabó la contradicción fundamental entre capital y trabajo; que terminaron las luchas de clases en función de esta nueva "elite" de trabajadores que surgen y que se sienten partícipes del proceso productivo. Conforme a esta visión, concepción y ejecución finalmente se unen. En este sentido, este "nuevo paradigma productivo" estaría excento de la alienación intrínseca al modelo fordista. 
La llamada "Revolución Científico-Tecnológica establece que estarían surgiendo nuevos métodos de trabajo alternativos al modelo taylor/fordista. La tesis fundamental de este "nuevo padrón de acumulación" indica caminos para la consolidación de una producción flexible con capacidad de responder a la variabilidad y a la complejidad cresciente de una demanda creada por la apertura al mercado internacional. Ejemplos de este tipo de métodos "flexibles", originados en Japón, son los denominados "Círculos de Control de Calidad", Sistema Just in Time/Kanban", entre otros.

Se produce, por lo tanto, una nueva integración pasiva, del conjunto de las clases trabajadoras, al orden comandado por el gran Capital. La autonomía, lejos de estar en función del trabajo y de la posibilidad de una vida emancipada, sólo existe en función del Capital.

Las formas que historicamente asumió la subsunción del trabajo al capital (de forma clara con el taylor/fordismo así como también en las formas conocidas hoy bajo el rótulo de "padrón de acumulación flexible") están identificadas al progresivo control - por parte de los capitalistas - sobre el proceso de trabajo. De esta manera, la actual subordinación del trabajo al capital se manifiesta en la constucción de una nueva eficacia de la racionalidad capitalista a partir de técnicas de gestión del capital sobre la fuerza de trabajo. Tal es el caso del los llamados "Círculos de Control de Calidad"; "Just In Time/Kanban", etc.

Dirá Fernandes Dias (1997, p.114-115):

"Todo esto aparece como una "revolución" científico-tecnológica lo que legitimaria el capitalismo y negaria la necesidad de los antagonismos clasistas, decretando la superfluidad de las clases trabajadoras. Al mismo tiempo en que lleva la descalificación del trabajador al máximo y caracteriza su dispensabilidad, ese proceso tiene la apariencia de recuperación y reintegración del saber operario. Todo eso marcado por la tentativa de tornar desnecesaria la actividad sindical en la 
perspectiva clasista y con eso, posibilitar que la hegemonía capitalista nazca en la cotidianidad del acto del trabajo".

Los principios fundantes del proceso de subordinación del trabajo al capital son mecanismos que objetivan garantizar el aumento de la productividad a través de la progresiva disminución de los costos, de la eliminación de las "porosidades" (o tiempos muertos) y del conjunto de fallas y errores que se presentan en la esfera de la producción inmediata $y$, fundamentalmente hoy con más claridad, el capital se propone ejercer un control instrumental sobre la subjetividad de los trabajadores. La reestructuración productiva en curso trae consigo -de manera implícitaun instrumento mediante el cual las clases dominantes objetivan recomponer la subalternidad política de las clases subalternas/trabajadoras a través de una recomposición/reformulación política de las formas de enfrentamiento entre las clases.

El fordismo revolucionó el uso de las fuerzas productivas y las relaciones de producción industriales durante la primera mitad del siglo $\mathrm{XX}$. No obstante, cabe resaltar que la revolución del fordismo trascendió la esfera productiva: este ha generado también, según vimos en páginas anteriores, la correspondencia antropológica que requeria la industria en masa. Así la racionalización fordista le dió sobrevalor a dos dimensiones del ser humano: como productor autómato de mercancías, característico de la fábrica taylorizada y como consumista. Así, esta reducción del bomo sapiens al homo oeconomicus, misión histórica del sistema productor de mercancías, ha orientado las potencialidades y necesidades del ser humano en función de la reproducción ampliada del capital. Así, el fordismo, conforme ha demostrado el propio Gramsci, fue aquella forma de hegemonía caracterizada como Revolución Pasiva que, a través de los mecanismos de coerción y consentimiento que implementó, posibilitó una extraordinaria expansión del capital y, simultáneamente, una retirada de las clases trabajadoras para el terreno económico - 
corporativo, abandonando la perspectiva clasista de construcción de la hegemonía ${ }^{5}$. Actualmente, la "reestructuración productiva" en curso apunta en el mismo sentido: el capital con su envolvimiento manipulatorio y cooptante genera el discurso según el cual se recupera la subjetividad del trabajador y se convierte en partícipe activo del proceso productivo, neutraliza, una vez más, el potencial emancipatório de las clases subalternas. La transformación del perfil del trabajador/trabajadora se convierte, nuevamente, una necesidad del capital. Para crear las condiciones de esta nueva fase del sistema productor de mercancías, cristalizado en la llamada "reestructuración productiva" se hace imprescindible, para el capital, desestructurar las identidades y los referenciales de clase asi como también reformular las relaciones de trabajo vigentes. Así, el "nuevo proyecto" construye la "solidaridad por la productividad" y 'des-construye' la "solidaridad de clase" que tiene un carácter esencialmente reivindicativo. La "autonomía" del trabajador sólo existe en función del capital. El discurso del "fin de los conflictos" entre capital y trabajo va ganando fuerza progresivamente. Hay, por lo tanto, una nueva integración pasiva al orden fetichista del capital.

Así, en la actualidad, la estrategia de la Revolución Pasiva se manifiesta fundamentalmente, en dos dimensiones de la esfera política: por la hegemonia neoliberal a nivel del Estado y por llamada "reestrucutración

5 "Carente de referencias clasistas, la mayoría del movimiento social organizado, a escala planetaria, tiende, cada vez más, a integrarse pasivamente al orden, o sea: permanece prisionero de concepciones económico-corporativas, reduciendo sus intervenciones en las luchas sociales, privilegiando el campo corporativo, para intentar articular una defensa en el plano del empleo, de mejores salarios, etc. Y, en el campo de la política, lo actual es (y debe ser, desde el punto de vista del Capital) tomado como el único horizonte posible. Negociar a cualquier precio pasa a ser la idea dominante, la idea 'moderna'."'(Fernandes Dias, 1997 b: 119) 
productiva" en el sistema de las fuerzas productivas (Braga, 1997a, p.272). Las transformaciones en curso son presentadas como inexorables, como si la mano invisible de Adam Smith decidiera el curso fatal de la historia.

ABSTRACT: The objective of this article is to consider some gramscians categories and to update them as categories of analysis of contemporary capitalism. We will regard the aspect concerning the actual productive restructuring as the most important topic in this work.

First, we intend to recover the concept of hegemony contained in the formulations of Prision Writting Book. We will consider still at this point, organic crise and passive revolution categories. This categories are effectives to understand the crises of capital and its tentatives of resolution, just as the estrategic intervention of subordinated classes to construct its hegemony.

We develop, at a second moment by also using previous elements, some thesis included in texts of "Americanism and Fordism".

Finally, we raise that the contemporary capitalism -under the ideological appearence of "tecno-scientific revolution" - assumes a passive estrategy wich esential feature is the transformism, a distinctive aspect, according with Gramsci, to name the Passive Revolution.

KEYWORDS: Gramsci; organic crise; hegemony; passive revolution; capistalism; fordism; productive restructuring.

\section{BIBLIOGRAFIA}

ANNUNZIATO, F. R. "Il fordismo nella critica di Gramsci e nella realtà statunitense contemporanea" in Revista Crítica Marxista No. 6. 1989

BOLOGNA, S./ RAWICK, G.P./ GOBBINI, M./ NEGRI, A./ FERRARI BRAVO, L./ GAMBINO, F. "OPERAI E STATO. Lotte operaie e riforma dello stato capitalistico tra rivoluzione d'Ottobre e New Deal. Feltrinelli Editore. Milano, 1980. 
La actualidad de las categorias gramscianas para el análisis de la reestructuración... 181

BUCI-GLUCKSMANN, C. Gramsi e o Estado, Paz e Terra. Rio de Janeiro, 1985.

"Sobre os problemas políticos da transição: classe operária e revolução passiva" In Ferri, F. (Instituto Gramsci) Política e História em Gramsci, Vol. I . Civilização Brasileira. Rio de Janeiro, 1978.

BRAGA, R. Restauração do Capital: Um estudo sobre a crise contemporânea. Xamã. São Paulo, 1997 (a).

"A trajetória regulacionista entre a ruptura e a resignação. Elementos críticos." Relatório de pesquisa. Mimeo. 1997 (b)

BRAVERMAN, H. Trabalho e Capital Monopolista. ZAHAR Editores. Rio de Janeiro, 1981.

BURAWOY, M. A transformação dos regimes frabris no capitalismo avançado. Revista Brasileira em Ciências Sociais No. 13. Junho de 1990.

CHOMSKY, N. / DIETERICH, H. La sociedad global. Educación, mercado y democracia. Oficina de Publicaciones. Universidad de Buenos Aires. Buenos Aires, 1996.

CORIAT, B. Ciencia, Técnica y Capital. H. Blume ediciones. Madrid, 1976.

El taller y el cronómetro. Ensayo sobre el taylorismo, el fordismo y la producción en masa. Siglo XXI editores. Madrid, 1985.

Pensar pelo avesso. Revan / UFRJ . Rio de Janeiro, 1994.

CLARKE, S. "Crise do fordismo ou crise da social democracia? In: Revista Lua Nova No. 24. Setembro, 1991.

"New utopias for old: Fordist dreams and Post-Fordist fantasies" In: Revista Capital \& Class N. 42. Winter, 1990

DE FELICE, F. "Revolução passiva, fascismo, americanismo em Gramsci. In Ferri, F. (Instituto Gramsci) Politica e História em Gramsci, Vol. I . Civilização Brasileira. Rio de Janeiro, 1978.

DIAS, E. F. "As transformações do mundo do trabalho: revolução científico-tecnológica e/ou nova dominação?” Mimeo. Campinas, 1995. 
"Cidadania e racionalidade de classe" In Revista Universidade $e$ Sociedade. No. 12 São Paulo, Junho de 1996 (a) "Hegemonía, racionalidade que se faz história" in O Outro Gramsci. Xamã Editora. São Paulo, 1996 (b).

"Americanismo e Revolução Russa: formas da revolução passiva” In: Revista Universidade e Sociedade, No.13. São Paulo, Julho de 1997.

FORD, H. Minba vida e minba obra. Companhia Editora Nacional. RioSão Paulo, 1926.

GRAMSCI, A. Concepşão dialética da bistória. Civilização Brasileira. Rio de Janeiro, 1995.

Maquiavel, a politica e o Estado Moderno. Civilização Brasileira. Rio de Janeiro, 1976.

Os intelectuais e a organização da cultura. Civilização Brasileira,. Rio de Janeiro, 1978.

"Pasado y Presente" Granica, edições. Buenos Aires, 1982.

TAYLOR, F. Princípios de Administraşão Científica. Atlas. São Paulo, 1980. TRONTI, M./ PANZIERI, R./ BOLOGNA, S./ SOHN-RETHEL, A./ PALLOIX, C. Processo de trabalho e estratégias de classe. Zahar Editores. Rio de Janeiro, 1982.

SOUZA, A. T. "A Crise Contemporânea e a Nova Ordem Mundial" In: Revista Universidade e Sociedade No. 6. Fevereiro, 1994. "Sobre o americanismo e fordismo de Antonio Gramsci". IFCH UNICAMP. Textos Didáticos No. 5. São Paulo, Fevereiro de 1992. 